\title{
Differences in local and systemic inflammatory markers in patients with obstructive airways disease
}

\author{
*Lisa Tilemanna, Lena Gindnerb, Franz Meyerc, Joachim Szecsenyi ${ }^{\mathrm{b}}$, Antonius Schneider ${ }^{\mathrm{a}}$ \\ a Technische Universität München, Klinikum rechts der Isar, Institute of General Practice, Munich, Germany \\ ${ }^{b}$ Department of General Practice and Health Services Research, University of Heidelberg, Heidelberg, Germany \\ 'Department of Cardiology, Angiology, Respiratory Medicine, University of Heidelberg, Medical Center, Heidelberg, Germany
}

Originally submitted 27th March 2010; resubmitted 16th December 2010; revised 13th April 2011; accepted 7th May 2011;

online 2nd August 2011

\begin{abstract}
Background: Asthma and chronic obstructive pulmonary disease (COPD) are characterised by airway and systemic inflammation, but little is known about differences and similarities in inflammatory markers in patients with obstructive airways disease.

Methods: In 210 adult patients presenting to their general practitioners with symptoms suggestive of obstructive airways disease, lung function, fractional exhaled nitric oxide ( $\mathrm{FE}_{\mathrm{NO}}$ ), blood eosinophils, and serum levels of high-sensitivity C-reactive protein (hs-CRP) and IgE were measured.

Results: hs-CRP levels were increased in COPD patients $(p=0.009)$, whereas FENO, IgE, and eosinophils were increased in patients with asthma ( $p=0.009, p=0.041$, and $p=0.009$, respectively). In the ROC analysis, hs-CRP had the largest area under the curve (AUC=0.651; $95 \%$ confidence interval $(\mathrm{Cl}) 0.552$ to 0.749 ), with a specifity of $83 \%$ and a sensitivity of $42 \%$ for the diagnosis of COPD. FENO was the most accurate marker in the diagnosis of asthma ( $A \cup C=0.618 ; 95 \% \mathrm{Cl} 0.529$ to 0.706 ). Serum hs-CRP levels correlated with the number of smoking pack-years $(r=0.218, p=0.001)$ and inversely with lung function parameters.

Conclusions: Levels of serum hs-CRP, IgE, blood eosinophils, and FENO identify distinct aspects of local and systemic inflammation in patients with obstructive airways disease. This might help to differentiate between asthma and COPD in primary care patients when spirometry is not available.

(C) 2011 Primary Care Respiratory Society UK. All rights reserved.

L Tilemann et al. Prim Care Respir J 2011; 20(4): 407-413

http://dx.doi.org/10.4104/pcrj.2011.00069
\end{abstract}

Keywords asthma, COPD, diagnosis, inflammatory markers, local, systemic

See linked editorial by Thomas and Taylor on pg 349

\section{Introduction}

Asthma and chronic obstructive pulmonary disease (COPD) are increasingly important chronic airway diseases. The use of the patient history - including signs and symptoms, smoking status, and allergy presentation - may help to differentiate disease characteristics, as well as pulmonary function testing with an assessment of reversibility and bronchial hyperresponsiveness. ${ }^{1}$ However, improvement in diagnostic accuracy is needed. The present approach in understanding and differentiating asthma and COPD is the use of inflammatory markers since both diseases are characterised by local and systemic inflammatory processes. As a marker of eosinophilic airway inflammation, fractional exhaled nitric oxide ( $\mathrm{FE}_{\mathrm{NO}}$ ) is increased in patients with asthma. ${ }^{2,3}$ Serum immunoglobulin $\mathrm{E}(\mathrm{lgE})$ levels are known to be associated with asthma, ${ }^{4,5}$ and a significant increase in the number of peripheral blood eosinophils was found in patients with asthma that correlated with the clinical severity of asthma and pulmonary function. ${ }^{6}$ Elevated levels of C-reactive protein (CRP) are established in $\mathrm{COPD}^{7-9}$ but, in asthma, the results have been inconsistent. In recent studies high-sensitivity CRP concentrations (hs-CRP) were significantly higher in asthma patients than in controls without obstructive airways disease (OAD). 10,11 Other workers have reported that elevated levels of hs-CRP were associated with respiratory symptoms and nonallergic asthma but not with allergic asthma or bronchial hyperresponsiveness. ${ }^{12}$ Higashimoto et al. investigated

\footnotetext{
* Corresponding author: Dr Lisa Tilemann, Technische Universität München, Klinikum rechts der Isar, Institute of General Practice, Orleansstr. 47, Munich 81667, Germany. Tel: +49-89-6146589-13 Fax: +49-89-6146589-15 E-mail: talysat@gmx.de
} 
differences in systemic inflammation between asthma and COPD and found similar hs-CRP levels in asthma and COPD patients..$^{13}$ Significant differences in hs-CRP concentrations between OADs have not yet been reported.

There have been various attempts to predict the response to treatment by inflammatory markers ${ }^{14-16}$ and to predict the progress of asthma or COPD. ${ }^{17-20}$ However, similarities and differences in inflammatory patterns between asthma and COPD and the diagnostic accuracies of most inflammatory markers have not been determined. The aim of the present study was to evaluate differences in airway and systemic inflammatory markers among primary care patients with asthma, COPD, and partially reversible airway obstruction. This might assist the differentiation between asthma and COPD in primary care.

\section{Methods}

\section{Study population and design}

Two hundred and ten adults presenting to their general practitioners (GPs) for the first time with complaints suggestive of OAD were consecutively included. The patients had dyspnoea, coughing and/or expectoration persisting for at least 2 months. The GPs were advised to exclude subjects with respiratory tract infections in the six weeks prior to investigation. The other exclusion criteria included the wellknown contraindications for bronchodilator reversibility testing or bronchial provocation - namely, pregnancy, untreated hyperthyroidism, unstable coronary artery disease, and cardiac arrhythmia.

Over a period of two weeks, subjects were referred to the lung function laboratory of the University Medical Hospital for further investigation. Structured medical histories were documented. All subjects underwent body plethysmography on the day of hs-CRP, IgE, blood eosinophil and FENO measurements. In 11 subjects (5.2\%), anti-asthma treatment with inhaled corticosteroids had already been started by the referring GP because of severe airway obstruction. Patients were instructed not to use any bronchodilator or inhaled steroid and to stop smoking $12 \mathrm{hrs}$ before visiting the lung function laboratory. The number of pack-years was calculated as years of smoking/20 $\mathrm{x}$ number of daily cigarettes. Subjects were categorised as never smokers if they had smoked less than 1 pack-year by the time of the study. Body mass index (BMI) was calculated as weight $(\mathrm{kg}) / \mathrm{square}$ of height $\left(\mathrm{m}^{2}\right)$. The study was approved by the Medical Ethics Committee of the University of Heidelberg and all patients gave written consent. Measurement of FENO, hs-CRP, IgE and eosinophils Patients underwent measurement of FENO using a NioxMino ${ }^{\oplus}$ analyser (Aerocrine AG, Solna, Sweden) at a mouth flow rate of $50 \mathrm{~mL} / \mathrm{s}$ over $10 \mathrm{~s}$ and a pressure of $10 \mathrm{cmH}_{2} \mathrm{O}$ according to the guideline recommendation. ${ }^{21}$ This procedure was performed at the lung function laboratory of the University Medical Hospital before investigation with body plethysmography and bronchial provocation as forced inspiratory and expiratory manoeuvres can lead to distorted FENO results. ${ }^{22}$ Samples of peripheral venous blood were collected. Serum hs-CRP levels were measured with a high-sensitivity nephelometric assay (ADVIA ${ }^{\circledast} 2400$ Hematology System, Siemens Healthcare Diagnostics, Deerfield, IL, USA) and IgE levels with an electro-chemiluminescence assay (Modular Analytics EVO solution, Roche Diagnostics, Switzerland). Eosinophil counts were performed with flow cytometry (ADVIA ${ }^{\circledast} 2120$ Hematology System, Siemens Healthcare Diagnostics). Owing to technical difficulties, there were 13 missing values for eosinophils. In addition, 54 FENO measurements were missing as FENO was initially planned to be part of a diagnostic study only. . $^{23}$

\section{Pulmonary function testing}

All 210 subjects with respiratory symptoms suggestive of an OAD underwent body plethysmography in the lung function laboratory of the University Medical Hospital according to standard protocols. ${ }^{24}$ Lung function reference values corrected for sex, age, and height were used.

Patients with forced expiratory volume in one second $\left(\mathrm{FEV}_{1}\right)<80 \%$ of predicted received a bronchodilation test with an additional whole body plethysmography 20 mins

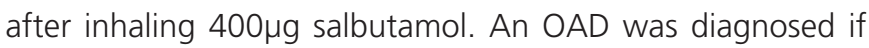
$\mathrm{FEV}_{1} /$ vital capacity $(\mathrm{VC})$ was $\leq 0.7$.

The obstruction was classified as irreversible (indicating COPD) if the postbronchodilator $\mathrm{FEV}_{1}$ was less than $12 \%$ compared with baseline and was below $200 \mathrm{~mL}$. The obstruction was classified as fully reversible (indicating 'asthma') if the degree of reversibiliy in $\mathrm{FEV}_{1}$ was $>12 \%$ and $>200 \mathrm{~mL}$ from baseline and lung volumes returned to the predicted normal range. An incomplete bronchodilator response (indicating partial reversibility) was considered to be present if the bronchodilation response was $>12 \%$ and $>200 \mathrm{~mL}$ compared with baseline but lung volumes remained below the predicted levels.

If there was no obstruction in the first lung function test, a bronchial provocation test with methacholine was performed according to the American Thoracic Society guidelines to determine bronchial hyperresponsiveness. ${ }^{25}$ Asthma was diagnosed if there was a fall of $>20 \%$ in $\mathrm{FEV}_{1}$ after inhaling methacholine stepwise up to the maximum concentration $\left(\mathrm{PC}_{20}\right.$ $\leq 16 \mathrm{mg} / \mathrm{mL}$ ).

\section{Statistical analysis}

The data were analysed with SPSS 15.0 for Windows. Baseline data are presented as median or mean \pm SD. The Mann-Whitney $U$ test was used to analyse differences between the two groups and correlations were analysed using Spearman's rank correlation test; $p$ values $<0.05$ were considered statistically significant. Receiver operating characteristic (ROC) curves were plotted, which allowed a graphical representation of sensitivity and specificity. The 
corresponding areas under the curve (AUC) were calculated to estimate the diagnostic accuracy of each inflammatory marker. The AUC can range from 0.5 (model discrimination no better than by chance) to 1.0 (perfect model discrimination). Boxplots were constructed to illustrate the dispersion of each inflammatory marker by diagnosis. Cut-off values were determinated by identifying the concentration of the respective marker with the highest sum of sensitivity and specifity. hs-CRP values were divided into quartiles from the lowest to the highest levels for further analysis.

In some cases, asthma and COPD could hardly be differentiated. Repeated measurements after trials of medication were required, particularly to identify asthma with fixed obstruction. As long-term follow-up was not possible for organisational reasons, we performed an additional analysis in which never-smoking subjects with an incomplete or negative bronchodilation test were labelled as asthma patients.

\section{Results}

\section{Characteristics and inflammatory patterns}

Patients with COPD $(n=36)$ were significantly older $(p<0.001)$, had accumulated more pack-years $(p<0.001)$, and had lower lung function parameters than patients with asthma $(n=86)$ and those with no OAD $(n=75)$. The characteristics of COPD patients were similar to those of patients with partial reversibility of airflow obstruction ( $n=13$; Table 1$)$. Patients with asthma differed in age $(p<0.001)$, number of pack-years $(p<0.001)$, and lung function parameters from those with partial reversibility. The BMI of asthma patients was lower than that of COPD patients.

COPD patients had significantly higher levels of hs-CRP than asthma patients $(p=0.003)$ and subjects with no OAD $(p=0.018$; Table 2$)$. There were no significant differences in any of the inflammatory markers between COPD patients and patients with partial reversibility of airflow obstruction. Asthma patients had higher levels of $\mathrm{FE}_{\mathrm{NO}}, \mathrm{IgE}$, and blood eosinophils than COPD patients $(p=0.004, p=0.013$, and $p=0.007$, respectively). Between asthma patients and those with partial reversibility of airflow obstruction, there was a difference in FENO concentrations but not in hs-CRP and IgE levels or eosinophils. Even though the differences in inflammatory markers between asthma patients and those with COPD were significant, the box plots indicated a substantial degree of overlap in the inflammatory markers by diagnosis (Figure 1).

In an additional analysis, six never-smoking subjects without reversibility of airflow obstruction and two neversmoking subjects with partial reversibility of airflow obstruction were redefined as having asthma (with fixed obstruction). The significance levels of differences in levels of inflammatory markers between asthma and COPD remained unaltered for hs-CRP $(p=0.003)$, increased for FENO $(p=0.002)$, and decreased for $\lg E(p=0.023)$ and eosinophils $(\mathrm{p}=0.039$; not shown).

There were no significant differences between male and female patients in inflammatory markers except for IgE

Table 1. Descriptive characterisation of patients with asthma, COPD, partial reversibility, and no OAD

\begin{tabular}{|c|c|c|c|c|}
\hline & $\begin{array}{l}\text { Asthma } \\
(\mathrm{n}=86)\end{array}$ & $\begin{array}{l}\text { COPD } \\
(n=36)\end{array}$ & $\begin{array}{l}\text { Partial reversibility } \\
(n=13)\end{array}$ & $\begin{array}{l}\text { No OAD } \\
(\mathrm{n}=75)\end{array}$ \\
\hline Age (yrs), mean \pm SD & $38.0 \pm 14.6^{* * / \S \S}$ & $56.8 \pm 11.7$ & $57.9 \pm 11.2$ & $42.3 \pm 14.4^{* * / \S \S}$ \\
\hline Person-years $(n)$, mean \pm SD & $6.4 \pm 12.9^{* * / \S \S}$ & $31.2 \pm 23.1$ & $21.8 \pm 17.0$ & $6.7 \pm 12.2^{* * / \S \S}$ \\
\hline \multicolumn{5}{|l|}{ Smoking status, n (\%) } \\
\hline Current smokers & $17(19.8)$ & $17(47.2)$ & $8(61.5)$ & $21(28.0)$ \\
\hline Past smokers & $11(12.8)$ & $13(36.1)$ & $3(23.1)$ & $9(12.0)$ \\
\hline Never smokers & $58(67.4)$ & $6(16.7)$ & $2(15.4)$ & $45(60.0)$ \\
\hline Male, n (\%) & $31(36.0)$ & $17(47.2)$ & $7(53.8)$ & $31(41.3)$ \\
\hline BMI $\left(\mathrm{kg} / \mathrm{m}^{2}\right)$, mean $\pm \mathrm{SD}$ & $24.5 \pm 4.0^{*}$ & $26.6 \pm 4.1$ & $26.3 \pm 4.5$ & $25.6 \pm 4.8$ \\
\hline \multicolumn{5}{|l|}{ Pulmonary function, mean \pm SD } \\
\hline VC, \% predicted & $105.4 \pm 11.5^{\star *} / \S \S$ & $90.7 \pm 17.7$ & $92.7 \pm 18.2$ & $107.8 \pm 13.5^{* * / \S \S}$ \\
\hline $\mathrm{FEV}_{1}, \%$ predicted & $99.7 \pm 12.0^{* * / \S \S}$ & $69.1 \pm 17.1$ & $67.6 \pm 17.2$ & $106.3 \pm 12.8^{* * / \S \S}$ \\
\hline $\mathrm{FEV}_{1} N \mathrm{NC}, \%$ & $78.2 \pm 7.2 * * / \S \S$ & $59.9 \pm 9.0$ & $57.5 \pm 8.7$ & $81.0 \pm 6.0 * * / \S \S$ \\
\hline ITGV, \% predicted & $119.8 \pm 24.0 * * / \S$ & $140.2 \pm 29.5$ & $145.6 \pm 29.5$ & $118.7 \pm 18.8 * * / \S$ \\
\hline $\mathrm{RV}, \%$ predicted & $125.0 \pm 24.3^{* *} / \S \S$ & $166.1 \pm 46.0$ & $171.2 \pm 44.4$ & $121.6 \pm 27.6^{* * / \S \S}$ \\
\hline $\mathrm{MEF}_{25}, \%$ predicted & $79.8 \pm 20.8^{* * / \S \S}$ & $31.5 \pm 12.1$ & $28.8 \pm 11.4$ & $93.3 \pm 25.4^{* * / \S \S ~}$ \\
\hline $\mathrm{MEF}_{50}, \%$ predicted & 66.9. $\pm 22.7^{* * / \S \S ~}$ & $23.8 \pm 9.0$ & $23.0 \pm 10.1$ & $78.5 \pm 28.4^{* * / \S \S}$ \\
\hline
\end{tabular}




\begin{tabular}{|c|c|c|c|c|}
\hline & Asthma & COPD & Partial reversibility & No OAD \\
\hline \multicolumn{5}{|l|}{ hs-CRP (mg/L) } \\
\hline Mean $\pm \mathrm{SD}(95 \% \mathrm{Cl}$ of mean) & $1.9 \pm 3.1^{* *}(1.2$ to 2.6$)$ & $4.7 \pm 7.2(2.2$ to 7.1$)$ & $5.6 \pm 11.0(0.0$ to 12.3$)$ & $2.3 \pm 2.7^{*}(1.7$ to 2.9$)$ \\
\hline Median & 1.0 & 2.0 & 1.0 & 1.0 \\
\hline \multicolumn{5}{|l|}{ FENO (ppb) } \\
\hline Mean $\pm \mathrm{SD}(95 \% \mathrm{Cl}$ of mean) & $40.1 \pm 46.9 * * / \S(29.1$ to 51.1$)$ & $18.5 \pm 14.7(12.5$ to 24.5$)$ & $19.6 \pm 17.6(6.1$ to 33.1$)$ & $25.3 \pm 16.4^{*}$ (20.6 to 30.0$)$ \\
\hline Median & 23.0 & 14.5 & 13.0 & 21.0 \\
\hline \multicolumn{5}{|l|}{ Eosinophils (\%) } \\
\hline Mean \pm SD $(95 \% \mathrm{Cl}$ of mean) & $4.0 \pm 3.1^{* *}(3.3$ to 4.7$)$ & $2.6 \pm 1.4(2.1$ to 3.1$)$ & $2.8 \pm 1.8(1.7$ to 3.9$)$ & $3.2 \pm 1.8(2.8$ to 3.6$)$ \\
\hline Median & 3.2 & 2.3 & 2.8 & 3.0 \\
\hline \multicolumn{5}{|l|}{$\operatorname{lgE}(\mathrm{U} / \mathrm{mL})$} \\
\hline Mean \pm SD $(95 \% \mathrm{Cl}$ of mean) & $173.2 \pm 266.4^{*}(116.1$ to 230.3$)$ & $80.4 \pm 113.1$ (42.1 to 118.7$)$ & $131.0 \pm 262.6(0.0$ to 289.7$)$ & $129.9 \pm 242.3(74.2$ to 185.6$)$ \\
\hline Median & 67.2 & 27.0 & 59.9 & 47.0 \\
\hline
\end{tabular}

\section{Figure 1. Box plots illustrating the distribution of (a) high-sensitivity C-reactive protein (hs-CRP), (b) fractional exhaled nitric oxide (FENO), (c) eosinophils and (d) IgE within the diagnostic groups. Boxes represent the median and interquartile range (IQR); whiskers represent observations $<1.5$ IQR outside the central box. Open circles represent outliers and asterisks represent extreme outliers}

a)

c)

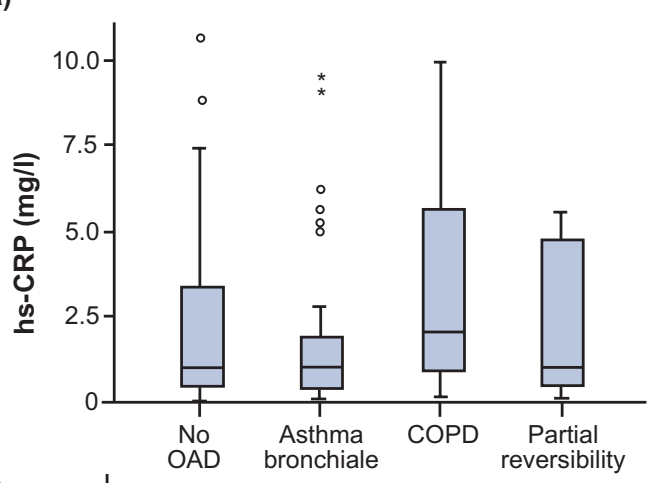

b)
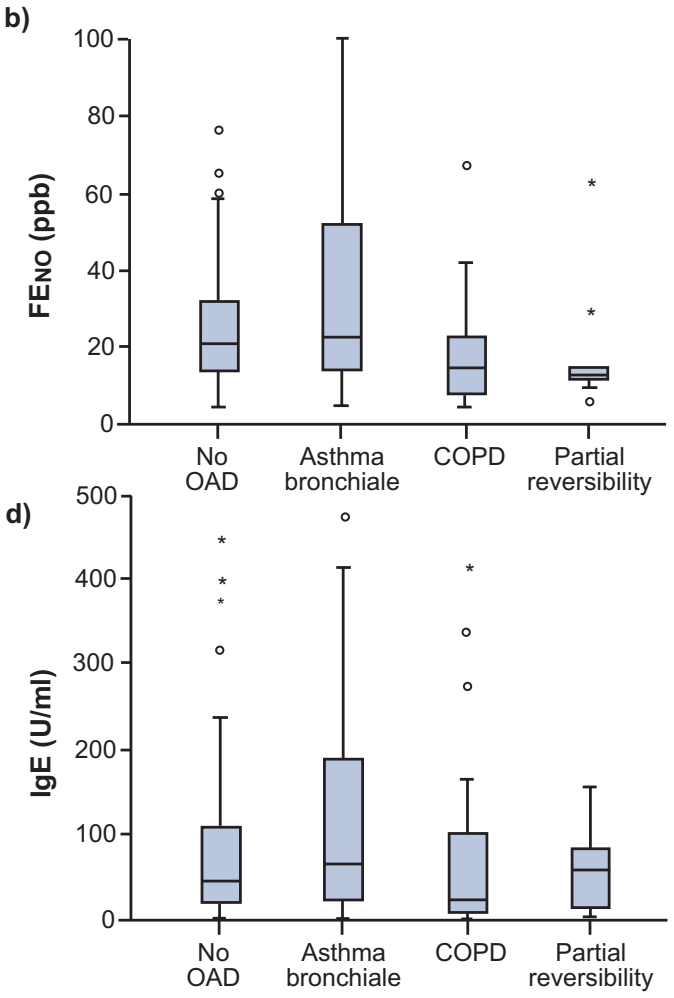

$(p=0.004)$. FENO concentrations and eosinophils were higher in current non-smokers (never smokers and ex-smokers) than in current smokers $(p<0.001$ and $p=0.015$, respectively). In contrast, there were no significant differences in hs-CRP and
IgE concentrations between current smokers and non-current smokers.

The ROC curves illustrate the diagnostic accuracy of each inflammatory marker (Figure 2). The AUC was highest for 
Figure 2. ROC curves illustrating the accuracy of (a) high-sensitivity C-reactive protein (hs-CRP) (AUC=0.651; $95 \% \mathrm{Cl}$ 0.552 to 0.749 ) in the diagnosis of chronic obstructive pulmonary disease COPD and the accuracy of (b) fractional exhaled nitric oxide ( $F E_{N O}$ ) (AUC=0.618; $95 \% \mathrm{Cl} 0.529$ to 0.706 ), (c) eosinophils ( $\mathrm{AUC}=0.602 ; 95 \% \mathrm{Cl} 0.520$ to 0.683 ), and (d) IgE (AUC=0.584; 95\% Cl 0.505 to 0.663 ) in the diagnosis of asthma

a)

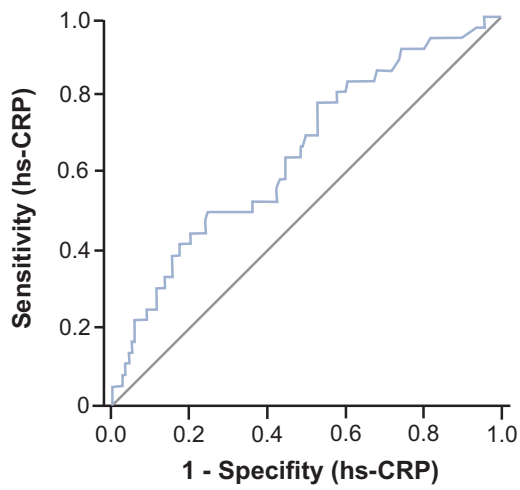

c)

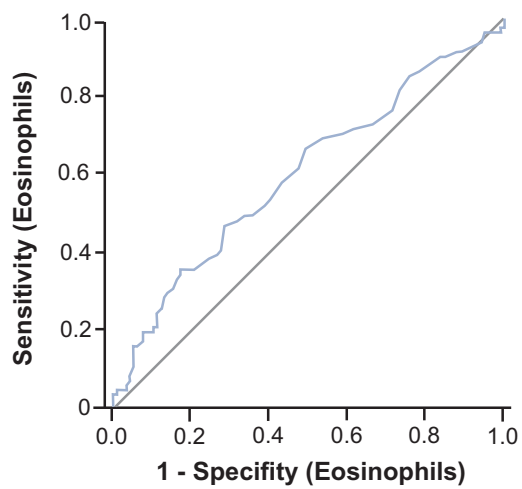

b)

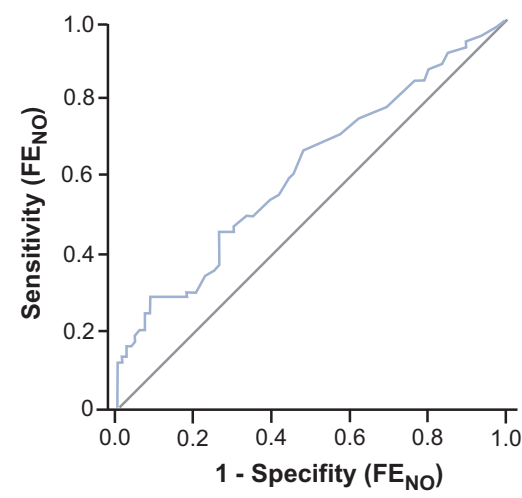

d)

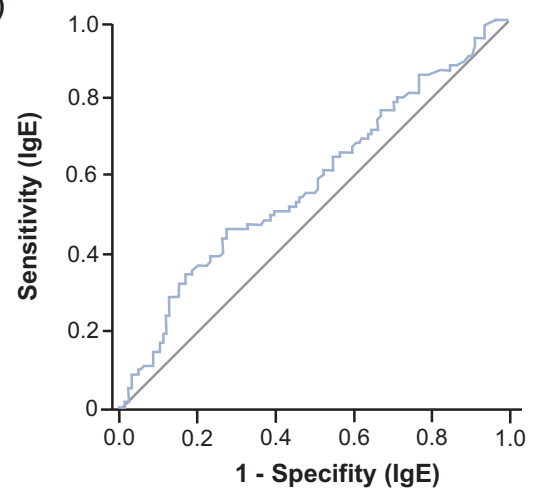

Table 3. Relation between hs-CRP, smoking history, BMI, and lung function parameters

\begin{tabular}{|c|c|c|c|c|c|c|c|c|}
\hline hs-CRP (mg/L)* & $n$ & $\begin{array}{l}\text { Pack-years (n) } \\
\text { Mean } \pm \text { SD }\end{array}$ & $\begin{array}{l}\text { BMI }\left(\mathrm{kg} / \mathrm{m}^{2}\right) \\
\text { Mean } \pm \text { SD }\end{array}$ & $\begin{array}{l}\text { VC pred (\%) } \\
\text { Mean } \pm \text { SD }\end{array}$ & $\begin{array}{l}\mathrm{FEV}_{1} \text { pred }(\%) \\
\text { Mean } \pm \mathrm{SD}\end{array}$ & $\begin{array}{l}\mathrm{FEV}_{1} / \mathrm{VC}(\%) \\
\text { Mean } \pm \mathrm{SD}\end{array}$ & $\begin{array}{l}\text { MEF50 pred (\%) } \\
\text { Mean } \pm \text { SD }\end{array}$ & $\begin{array}{l}\mathrm{MEF}_{25} \text { pred }(\%) \\
\text { Mean } \pm \text { SD }\end{array}$ \\
\hline$\leq 0.5$ & 54 & $6.4 \pm 12.1$ & $22.4 \pm 2.5$ & $103.6 \pm 15.1$ & $97.3 \pm 18.8$ & $77.2 \pm 10.9$ & $79.6 \pm 32.8$ & $70.9 \pm 32.7$ \\
\hline$>0.5 \leq 1.115$ & 51 & $8.4 \pm 13.4$ & $24.9 \pm 3.5$ & $103.8 \pm 16.3$ & $96.9 \pm 22.3$ & $75.4 \pm 12.2$ & $75.0 \pm 33.9$ & $64.6 \pm 32.1$ \\
\hline$>1.115 \leq 2.8$ & 54 & $11.7 \pm 17.2$ & $26.3 \pm 3.9$ & $104.5 \pm 12.9$ & $96.4 \pm 16.5$ & $74.7 \pm 09.8$ & $73.5 \pm 27.3$ & $57.8 \pm 23.0$ \\
\hline$>2.8$ & 51 & $20.6 \pm 23.7$ & $28.0 \pm 5.2$ & $99.8 \pm 16.5$ & $88.4 \pm 21.4$ & $71.6 \pm 11.9$ & $64.2 \pm 32.6$ & $50.1 \pm 32.8$ \\
\hline $\mathrm{p}$ value & & 0.001 & $<0.001$ & 0.099 & 0.006 & 0.002 & 0.007 & $<0.001$ \\
\hline
\end{tabular}

hs-CRP concentrations were categorised in quartiles.

$\mathrm{BMI}=$ body mass index; $\mathrm{FEV}_{1}=$ forced expiratory volume in one second; $\mathrm{hS}-\mathrm{CRP}=$ high-sensitivity $\mathrm{C}$-reactive protein; $\mathrm{MEF}_{25}=$ =maximum expiratory flow rate at $25 \%$ of vital capacity; MEF50=maximum expiratory flow rate at $50 \%$ of vital capacity; pred=predicted; $V C=v i t a l$ capacity

hs-CRP in the diagnosis of COPD (AUC $=0.651 ; 95 \% \mathrm{Cl} 0.552$ to 0.749 ). The best cut-off values to discriminate between COPD and no COPD were hs-CRP concentrations of $2.39 \mathrm{mg} / \mathrm{L}$ and $3.5 \mathrm{mg} / \mathrm{L}$. The lower cut-off at $2.39 \mathrm{mg} / \mathrm{L}$ resulted in a specificity of $75 \%$, sensitivity of $50 \%$, negative predictive value (NPV) of $88 \%$ and positive predictive value (PPV) of $30 \%$. At a concentration of $3.5 \mathrm{mg} / \mathrm{L}$ the specificity was $83 \%$, sensitivity was $42 \%$, NPV was $87 \%$, and PPV was $33 \%$. FENO was the best marker in the diagnosis of bronchial asthma (AUC $=0.618 ; 95 \% \mathrm{Cl} 0.529$ to 0.706 ), and the optimal cut- off at $46 \mathrm{ppb}$ had a specificity of $92 \%$, sensitivity of $29 \%$, PPV of $71 \%$, and NPV of $65 \%$. The AUC for blood eosinophils was 0.602 ( $95 \% \mathrm{Cl} 0.520$ to 0.683 ). The optimal cut-off was at $4.15 \%$ with a specificity of $83 \%$, sensitivity of $36 \%$, PPV of $59 \%$, and NPV of $65 \%$. IgE had the smallest AUC (AUC $=0.584$ (95\% Cl 0.505 to 0.663$)$. The optimal cut-off was at $90 \mathrm{U} / \mathrm{mL}$ with a specificity of $73 \%$, sensitivity of $47 \%$, PPV of $54 \%$, and NPV of $66 \%$. The ROC curves showed that hs-CRP and FENO in particular had some ability to discriminate patients. Nonetheless, the runs of the ROC curves also 


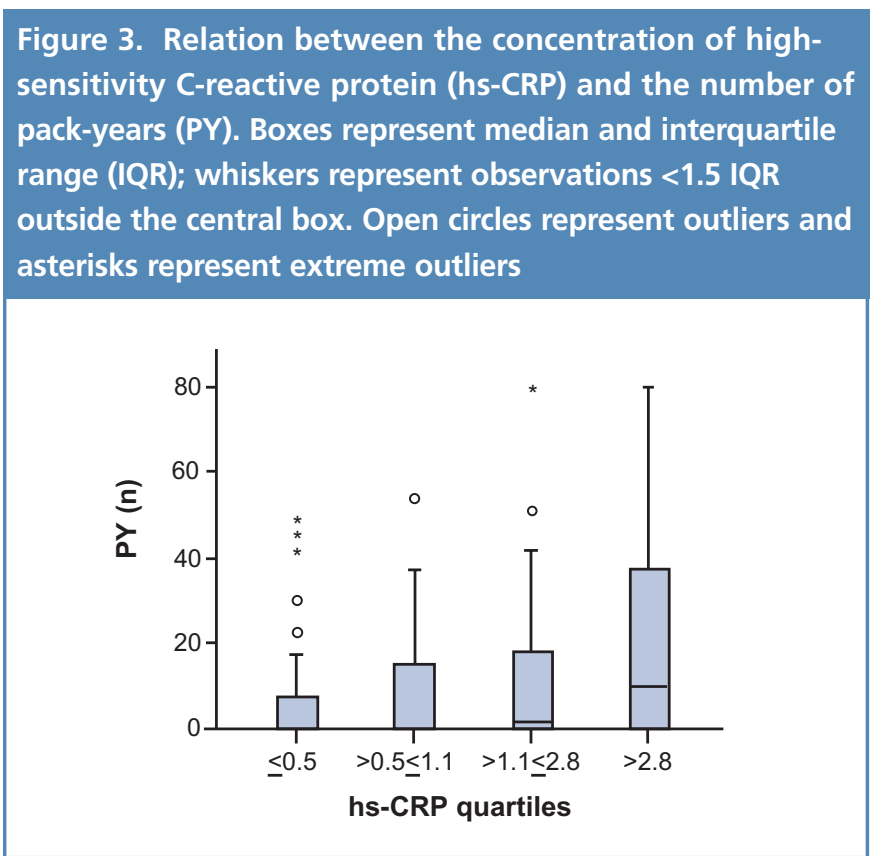

suggested that there was a large overlap between the measures by diagnosis.

\section{Correlations between hs-CRP, smoking history, lung function parameters and BMI}

hs-CRP concentrations were related to smoking history, lung function parameters, and BMI (Table 3). There was a significant correlation between hs-CRP levels and the number of pack-years $(p=0.001, r=0.218$, Figure 3$)$. When the analysis was restricted to patients with OAD (asthma, COPD, and partial reversibility of airflow obstruction), the correlation coefficient increased $(p<0.001, r=0.304)$. There was no significant association between hs-CRP levels and the number of pack-years in subjects without OAD (not shown). hs-CRP levels correlated positively with BMI $(p<0.001, r=0.474)$ and negatively with $F E V_{1}$ $(p=0.006, r=-0.190)$ and $F E V_{1} N C(p=0.002, r=-0.213)$.

\section{Correlations between hs-CRP, FENO, IgE and eosinophils}

There were correlations between blood eosinophils and IgE levels $(p<0.001, r=0.266)$, between blood eosinophils and $F E_{N O}$ concentrations $(p<0.001, r=0.284)$, and between $F_{N O}$ and $\lg E$ levels $(p<0.001, r=0.280)$. There were no significant correlations between the hs-CRP concentration and the levels of any of the other investigated inflammatory markers.

\section{Discussion}

The major finding of the present study is that there are distinctive inflammatory profiles in patients with asthma compared with COPD patients, thereby identifying different aspects of inflammation in OAD. Overall, hs-CRP had the highest diagnostic accuracy. In the diagnosis of asthma, FENO was superior to IgE and blood eosinophils. Nevertheless, there was some overlap between the inflammatory markers by diagnosis.

Low-level inflammation, as indicated by increased hs-CRP serum concentrations, has been described in both $\mathrm{COPD}^{7-9}$ and asthma. ${ }^{10,11}$ However, only one recent study has investigated differences in hs-CRP levels between patients with COPD and those with asthma. Higashimoto et al. compared systemic inflammatory markers in patients with $O A D$ and did not find a significant difference in hs-CRP concentrations between asthma and COPD patients. ${ }^{13}$ This is in contrast to the present findings of significantly increased hs-CRP levels in COPD patients. However, there are differences in the patients studied. In the present study, subjects mainly presented in the early stages of disease and only 11 patients were already receiving steroids. In contrast, Higashimoto et al. provided no information about the duration of disease and the current medication and, moreover, there were few lifetime non-smokers.

Significant differences in hs-CRP levels between subjects with severe asthma and controls without any respiratory symptoms have recently been demonstrated. ${ }^{10}$ In contrast, in a study by Takemura et al., hs-CRP levels were only increased in steroidnaive patients compared with controls. ${ }^{11}$ In our study the difference between asthma patients and without OAD (but with persistent respiratory symptoms) was not statistically significant; hs-CRP levels in both groups were very low.

In the present study there were six never-smoking patients without reversibility of airflow obstruction and 13 subjects with partial reversibility of airflow obstruction. A trial of inhaled steroids might have been helpful to differentiate between asthma and COPD in these patients. However, this was not the focus of the present study design with only a single lung function test. In an additional analysis the six never-smoking patients without reversibility of airflow obstruction and two never-smoking subjects with partial reversibility of airflow obstruction were labelled as asthma, although the significance levels of differences in inflammatory marker concentrations between asthma and COPD did not change to a great extent.

Data on inflammatory markers in patients with partial reversibility of airflow obstruction are currently scare. ${ }^{26,27}$ According to Papi et al., FENO levels were higher in patients with partial reversibility (in their study defined as an increase in $\mathrm{FEV}_{1}$ of $<12 \%$ but $>200 \mathrm{~mL}$ after $200 \mu \mathrm{g}$ inhaled salbutamol) than in those with no reversibility of airflow limitation. ${ }^{26}$ In a study by Fabbri et al., subjects with fixed airway obstruction and a history of asthma had more eosinophils in the peripheral blood and higher FENO levels than subjects with a history of COPD. ${ }^{27}$ In the present study the characteristics and inflammatory patterns of subjects with partial reversibility of airflow obstruction were similar to those of COPD patients. However, the differences in inflammatory patterns between patients with asthma and those with partial reversibility of airflow obstruction were not 
significant, except for $\mathrm{FE}_{\mathrm{NO}}$. This might be due to the small number of patients with partial reversibility of airflow obstruction in the study. Moreover, we are aware of the limitation of a single lung function test to determine a final diagnosis, as a negative or partial bronchodilator response can be due to fixed airway obstruction in asthma. Further studies are required to investigate the impact of inflammatory markers on the response to specific treatment, long-term management and outcome, particularly in this uncertain diagnostic group.

In all diagnostic groups there were numerous active smokers. The number of pack-years was positively correlated with hs-CRP levels. Thus, smoking history may influence the levels of inflammatory markers. The correlation was even stronger when the analysis was restricted to subjects with OAD. However, there was no significant association between the number of packyears and hs-CRP concentrations in subjects without OAD. It might be speculated that subjects with OAD are more likely to develop systemic low-level inflammation after tobacco exposure. Nevertheless, little is known about the reasons why some smokers develop chronic airway disease whereas others do not. In a cross-sectional survey, active smoking was associated with increased odds of elevated CRP levels. ${ }^{28}$ One group found a difference in hs-CRP concentrations between ex-smokers and current smokers ${ }^{13}$ whereas others did not. ${ }^{29}$ Also, in a recent epidemiological study, CRP levels did not vary by smoking status..$^{30}$ In the present study there were also no significant differences in hs-CRP concentrations between current smokers and non-current smokers. Overall, the accumulated pack years might have a higher impact on hs-CRP levels than current smoking status.

In conclusion, the results of the present study indicate that there are significant differences in inflammatory patterns between asthma and COPD. hs-CRP concentrations were increased in COPD patients, whereas blood eosinophils, FENO, and IgE levels were increased in patients with asthma. hs-CRP and $\mathrm{FE}_{\mathrm{NO}}$ had the highest ability to discriminate between patients with asthma and COPD.

While the use of FENO in the diagnosis of asthma seems to be about to find its way into daily practice, the other inflammatory markers still attract little attention. To date, mainly lung specialists have started to integrate FENO measurements into their daily work but it is not generally used in primary care. Economic evaluations suggest that $\mathrm{FE}_{\mathrm{NO}}$ might be a costeffective tool for diagnosing and monitoring asthma, so its more widespread use in primary care is feasible, when further studies can demonstrate diagnostic efficacy.

Currently, CRP is usually only determined if an exacerbation of COPD is suspected. Our data suggest that hs-CRP could be useful in differentiating between asthma and COPD. However, spirometry is already very efficient in the diagnosis of COPD and any added value of determining hs-CRP has not yet been demonstrated. Routine measurements of hs-CRP, IgE, and blood eosinophils for the diagnosis of asthma and COPD in a primary care setting would be useful only if they could also provide information about the response to treatment or disease progression.

\section{Handling editor}

Onno van Schayck

\section{Statistical review \\ Gopal Netuveli}

\section{Conflicts of interest}

The authors declare that they have no conflicts of interest in relation to this article.

\section{Contributorship}

All authors contributed to the realisation of this study and the preparation of the manuscript. In detail, LT analysed the data and wrote the manuscript. AS designed the study, helped analysing the data and writing the manuscript. LG was assistant investigator and helped gaining the data. FM interpreted the lung function testing and helped with writing. JS supported implementing the study.

\section{Funding}

The trial was funded by the Federal Ministry of Education and Research (BMBF), Germany, grant no. 01GK0515. The funding source had no involvement in the design, collection, analysis or interpretation of the data.

\section{References}

1. Bleecker ER. Similarities and differences in asthma and COPD. The Dutch hypothesis. Chest 2004;126(2 Suppl):93-5S. http://dx.doi.org/10.1378/ chest.126.2_suppl_1.93S

2. Alving $\mathrm{K}$, Weitzberg $\mathrm{E}$, Lundberg JM. Increased amount of nitric oxide in exhaled air of asthmatics. Eur Respir J 1993;6(9):1368-70.

3. Berkman N, Avital A, Breuer R, Bardach E, Springer C, Godfrey S. Exhaled nitric oxide in the diagnosis of asthma: comparison with bronchial provocation tests. Thorax 2005;60(5):383-8. http://dx.doi.org/10.1136/thx.2004.031104

4. Ahmad Al Obaidi AH, Mohamed Al Samarai AG, Yahya Al Samarai AK, Al Janabi JM. The predictive value of IgE as biomarker in asthma. J Asthma 2008;45(8):65463. http://dx.doi.org/10.1080/02770900802126958

5. Burrows B, Martinez FD, Halonen M, Barbee RA, Cline MG. Association of asthma with serum IgE levels and skin-test reactivity to allergens. N Engl J Med 1989;320(5):271-7. http://dx.doi.org/10.1056/NEJM198902023200502

6. Bousquet J, Chanez P, Lacoste JY, et al. Eosinophilic inflammation in asthma. N Engl J Med 1990;323(15):1033-9. http://dx.doi.org/10.1056/NEJM199010113231505

7. Gan WQ, Man SF, Senthilselvan A, Sin DD. Association between chronic obstructive pulmonary disease and systemic inflammation: a systematic review and a metaanalysis. Thorax 2004;59(7):574-80. http://dx.doi.org/10.1136/thx.2003.019588

8. Man SF, Connett JE, Anthonisen NR, Wise RA, Tashkin DP, Sin DD. C-reactive protein and mortality in mild to moderate chronic obstructive pulmonary disease. Thorax 2006;61(10):849-53. http://dx.doi.org/10.1136/thx.2006.059808

9. Sin DD, Man SF. Why are patients with chronic obstructive pulmonary disease at increased risk of cardiovascular diseases? The potential role of systemic inflammation in chronic obstructive pulmonary disease. Circulation 2003;107(11):1514-19. http://dx.doi.org/10.1161/01.CIR.0000056767.69054.B3

10. Qian FH, Zhang Q, Zhou LF, et al. High-sensitivity C-reactive protein: a predicative marker in severe asthma. Respirology 2008;13(5):664-9. http://dx.doi.org/ 10.1111/j.1440-1843.2008.01314.x

11. Takemura M, Matsumoto $H$, Niimi A, et al. High sensitivity C-reactive protein in asthma. Eur Respir J 2006;27(5):908-12.

12. Olafsdottir IS, Gislason T, Thjodleifsson B, et al. C reactive protein levels are increased in non-allergic but not allergic asthma: a multicentre epidemiological study. Thorax 2005;60(6):451-4. http://dx.doi.org/10.1136/thx.2004.035774

13. Higashimoto $Y$, Yamagata $Y$, Taya $S$, et al. Systemic inflammation in chronic obstructive pulmonary disease and asthma: similarities and differences. 